\title{
Renal distal tubular handling of sodium in central fluid volume homoeostasis in preascitic cirrhosis
}

\author{
G Sansoè, A Ferrari, E Baraldi, C N Castellana, M C De Santis, F Manenti
}

Gastroenterology Unit, Gradenigo Hospital, Torino, Italy G Sansoè

Department of Gastroenterology, Department of Internal Medicine, University of Modena, Modena, Italy A Ferrari

F Manenti

Department of Endocrinology, Department of Internal Medicine, University of Modena, Modena, Italy E Baraldi

M C De Santis

Department of Clinical Pharmacology, Department of Internal Medicine, University of Modena, Modena, Italy

C N Castellana

Correspondence to: Dr G Sansoè, Divisione di Gastroenterologia, Ospedale Gradenigo, C.so Regina Margherita 8, 10153 Torino, Italy.

Accepted for publication 2 June 1999

\begin{abstract}
BackgroundlAims-Patients with preascitic liver cirrhosis have an increased central plasma volume, and, for any given plasma aldosterone concentration, they excrete less sodium than healthy controls. A detailed study of the distribution of sodium reabsorption along the segments of the renal tubule, especially the distal one, is still lacking in preascitic cirrhosis. Methods-Twelve patients with ChildPugh class A cirrhosis and nine control subjects (both groups on a normosodic diet) were submitted to the following investigations: ( $a$ ) plasma levels of active renin and aldosterone; $(b)$ four hour renal clearance of lithium (an index of fluid delivery to the loop of Henle), creatinine, sodium, and potassium; (c) dopaminergic activity, as measured by incremental aldosterone response to intravenous metoclopramide.
\end{abstract}

Results-Metoclopramide induced higher incremental aldosterone responses, indicating increased dopaminergic activity in patients than controls, which is evidence of an increased central plasma volume (+30 min: 160.2 (68.8) $v 83.6$ (35.2) $\mathrm{pg} / \mathrm{ml}$, p<0.01; +60 min: 140.5 (80.3) $v 36.8$ (36.1) $\mathrm{pg} / \mathrm{ml}, \mathrm{p}<0.01)$. Patients had increased distal fractional sodium reabsorption compared with controls $(26.9(6.7) \% v 12.5$ $(3.4) \%$ of the filtered sodium load, $\mathbf{p}<0.05)$. In the patient group there was an inverse correlation between: $(a)$ absolute distal sodium reabsorption and active renin $(r-0.59, \mathrm{p}<0.05)$; (b) fractional distal sodium reabsorption and sodium excretion $(r-0.66, \mathrm{p}<0.03)$.

Conclusions-These data suggest that in preascitic cirrhosis the distal fractional tubular reabsorption of sodium is increased and critical in regulating both central fluid volume and sodium excretion.

(Gut 1999;45:750-755)

Keywords: kidney; sodium handling; lithium clearance; liver cirrhosis; dopamine; central fluid volume

Renal sodium retention occurs universally in patients with liver cirrhosis and ascites. Studies in experimental animals have consistently shown that sodium retention precedes ascites formation, emphasising the role of this renal functional abnormality in the pathogenesis of ascites. ${ }^{1-3}$

In patients with preascitic cirrhosis, subtle changes in body fluid compartments occur, namely an increase in circulating and/or central plasma volume. This has been shown by several experimental observations: increased distribution volume of ${ }^{131}$ I-labelled albumin and ${ }^{51} \mathrm{Cr}$-labelled erythrocytes ${ }^{4}$; increased central blood volume measured by radionuclide angiography ${ }^{5}$; increased end diastolic and end systolic left ventricular diameters ${ }^{6}$; suppression of the renin-angiotensin-aldosterone $\operatorname{axis}^{7-9}$; high plasma atrial natriuretic factor concentrations $^{10}$; increased endogenous dopaminergic activity. ${ }^{11}$

The role of dopaminergic activity as a marker of central volaemia is supported by the observation that plasma dopamine increases after saline infusion or head-out water immersion in normal men, ${ }^{12}{ }^{13}$ both procedures being able to increase central plasma volume acutely.

In cirrhotic patients and experimental animals, the increase in plasma volume is not only a critical event preceding the development of ascites; together with the systemic arterial vasodilatation, it is necessary for the full development of the hyperdynamic circulatory syndrome that maintains the portal venous hypertension in liver cirrhosis. ${ }^{14} 15$

Much controversy surrounds renal functional abnormalities in patients with preascitic cirrhosis. Some authors have documented a modest reduction in glomerular filtration rate at the preascitic stage. ${ }^{16-18}$ On the other hand, others have suggested that glomerular hyperfiltration occurs in well compensated cirrhotics. ${ }^{19}$ However, these patients are unable to handle a sodium load normally and develop ascites or oedema when intravenous saline solutions are given, indicating inappropriately elevated tubular sodium and water retention even in the presence of a preserved glomerular filtration rate. ${ }^{20-22}$ Normally most filtered sodium is reabsorbed in the proximal tubule, with fine adjustments to sodium excretion being carried out in the distal tubule. In preascitic cirrhosis,

Abbreviations used in this paper: $\mathrm{P}-\mathrm{Na}$, plasma sodium concentration; P-K, plasma potassium concentration; P-Li, plasma lithium concentration; $\mathrm{P}-\mathrm{Cr}$, plasma creatinine concentration; U-Na, urinary sodium concentration; U-K, urinary potassium concentration; U-Li, urinary lithium concentration; $\mathrm{U}-\mathrm{Cr}$, urinary creatinine concentration; $\mathrm{C}-\mathrm{Li}$, renal lithium clearance; $\mathrm{C}-\mathrm{Na}$, renal sodium clearance; $\mathrm{C}-\mathrm{K}$, renal potassium clearance; $\mathrm{C}-\mathrm{Cr}$, renal creatinine clearance; FE-Na, fractional sodium excretion; FE-K, fractional potassium excretion; FE-Li, fractional lithium excretion; Fl-Na, filtered sodium load; DD, absolute distal fluid delivery; DDNa, absolute distal sodium delivery; DRNa, absolute distal sodium reabsorption; DFRNa I, distal fractional sodium reabsorption I; DFRNa II, distal fractional sodium reabsorption II. 
the site in the nephron at which enhanced sodium reabsorption occurs is not known. ${ }^{23}$

Using the fractional lithium clearance technique, a method for determining proximal and distal reabsorption of sodium and water, ${ }^{24}{ }^{25}$ Simòn et $a l^{26}$ observed no difference in proximal tubular handling of sodium between preascitic cirrhotics and controls. On the other hand, Wong et $a l^{27}$ described in compensated cirrhosis decreased fractional lithium excretion, a marker of the fraction of filtered sodium load that escapes proximal tubular reabsorption.

The aims of this study were (a) to investigate the distribution of sodium reabsorption in the different renal tubular segments in order to identify the renal tubular site of early sodium retention and $(b)$ to evaluate the interaction between tubular function and central fluid volume, as studied by different markers of effective volaemia - that is, plasma active renin and endogenous dopaminergic activity ${ }^{11-13}$-in a homogeneous group of patients with well compensated preascitic cirrhosis.

\section{Materials and methods}

PATIENTS AND CONTROL SUBJECTS

Twelve patients (nine men, three women; age range 39-69 years) with biopsy proven ChildPugh A liver cirrhosis ${ }^{28}$ were studied. Patients with previous variceal bleeding, evidence of ascites, use of diuretics, heart failure, intrinsic renal disease, arterial hypertension, diabetes mellitus requiring drug treatment, or endocrine disease were excluded. No steroids, prostaglandin synthesis inhibitors, catecholamines, or antihypertensive drugs were administered for at least one month before the study. Nine healthy subjects (five men, four women; age range 27-65 years) were also studied as the control group. Patients and controls were not matched for weight, age, and size. Alcohol consumption had ceased in all patients at least three months previously and in control subjects was discontinued during the week before the study.

This study, which was performed in compliance with the 1975 Declaration of Helsinki ethical guidelines, was approved by the University of Modena ethics committee. All patients gave informed consent before participation in the study.

\section{PROTOCOL}

Before the study, control subjects and patients underwent an equilibration period of five days, during which they received a diet providing $120 \mathrm{mEq}$ sodium and $60 \mathrm{mEq}$ potassium daily.

At 2200 hours on the day before the study, $600 \mathrm{mg}$ lithium carbonate was administered orally. The following morning urine collection was commenced at 0800 hours. Blood samples were taken at the beginning and end of the urine collection period which lasted four hours (until 1200 hours). Urine was collected by spontaneous voiding. Water intake was fixed at 1.5 litres in the course of the four hour period. Patients and controls were maintained supine throughout the four hour clearance period. At midday, after urine collection, they were allowed to have a light meal. Blood samples at the beginning and at 1200 hours were analysed for plasma concentrations of sodium ( $\mathrm{P}-\mathrm{Na})$, potassium $(\mathrm{P}-\mathrm{K})$, lithium ( $\mathrm{P}-\mathrm{Li})$, and creatinine (P-Cr). Blood samples at the beginning of the clearance period were also analysed for plasma active renin and aldosterone concentrations. Urine samples were analysed for sodium (U-Na), potassium (U-K), lithium (U-Li), and creatinine (U-Cr) concentrations in the clearance period.

A further two hours of bed rest was commenced at 1400 hours. At the end of this period (time 0: 1600 hours) blood was withdrawn for determination of serum levels of aldosterone. A bolus of metoclopramide (10 mg intravenously; Plasil; Lepetit, Milan, Italy), a dopamine ${ }_{2}$-receptor antagonist, was injected, and blood collected at 30 and 60 minutes for measurement of plasma aldosterone. The increase in plasma aldosterone at 30 minutes after dopaminergic blockade is an accepted measure of endogenous dopaminergic activity, because of the tonic inhibitory effect of endogenous dopamine on mineralocorticoid secretion. ${ }^{29} 30$

ANALYTICAL METHODS

$\mathrm{P}-\mathrm{Na}, \mathrm{U}-\mathrm{Na}, \mathrm{P}-\mathrm{Li}, \mathrm{U}-\mathrm{Li}, \mathrm{P}-\mathrm{K}$, and U-K were measured with a flame photometer (Instrumentation Laboratory model 143, Paderno Dugnano, Italy). P-Cr and U-Cr were determined colorimetrically. ${ }^{31}$ Human active renin was determined in EDTA plasma. Active renin was determined by a two site immunoradiometric assay for the measurement of active renin protein (Nichols Institute Diagnostics, San Juan, California, USA). The normal range from our laboratory is $5-47 \mu \mathrm{U} / \mathrm{ml}$ in supine subjects and 7-76 $\mu \mathrm{U} / \mathrm{ml}$ when subjects are in the upright posture. Plasma aldosterone concentrations were evaluated by radioimmunoassay, using a kit from Sorin Biomedica (Saluggia, Italy) containing solid phase antibody coated tubes. Intra-assay variability was $7.4 \%$. The normal range from our laboratory is $10-150 \mathrm{pg} / \mathrm{ml}$ in the supine position and $35-300 \mathrm{pg} / \mathrm{ml}$ in the upright posture.

\section{CALCULATIONS}

$\mathrm{P}-\mathrm{Li}$ was calculated from the formula ${ }^{32}$ :

$$
\frac{\text { P-Li (pre) }-\mathrm{P}-\mathrm{Li} \text { (post) }}{2.3 \times \log \left(\frac{\text { P-Li (pre) }}{\text { P-Li (post) }}\right)}
$$

where P-Li (pre) and P-Li (post) were the plasma lithium concentrations at the beginning and end of the urine collection period respectively. $\mathrm{P}-\mathrm{Na}, \mathrm{P}-\mathrm{K}$, and $\mathrm{P}-\mathrm{Cr}$ were calculated as the means of the corresponding values at the beginning and end of the urine collection period. Lithium clearance (C-Li), sodium clearance $(\mathrm{C}-\mathrm{Na})$, potassium clearance $(\mathrm{C}-\mathrm{K})$, and creatinine clearance $(\mathrm{C}-\mathrm{Cr})$ were calculated. $\mathrm{C}-\mathrm{Cr}$ was used as an estimate of glomerular filtration rate. Fractional sodium excretion (FE-Na), fractional potassium excretion (FE-K), and fractional lithium excretion 
Table 1 Clinical and biochemical data of the 12 patients with liver cirrosis

\begin{tabular}{ll}
\hline Age (years) & $51(11)$ \\
Aetiology & \\
$\quad$ Alcoholic & 2 \\
Hepatitis C virus & 8 \\
Hepatitis B virus & 1 \\
$\quad$ Autoimmune hepatitis & 1 \\
Serum bilirubin (mg/dl) & $1.2(0.5)$ \\
Prothrombin time (\%) & $79(10)$ \\
Serum albumin (g/dl) & $3.8(0.3)$ \\
Alkaline phosphatase (IU/l) & $340(198)$ \\
ALT $(\mathrm{IU} / \mathrm{l}) \dagger$ & $208(119)$ \\
Platelet count (cell/mm $\left.{ }^{3}\right)$ & $89900(29300)$ \\
Oesophageal varices $(\mathrm{present} / \mathrm{absent})$ & $6 / 6$ \\
Blood urea nitrogen (mg/dl) & $35.7(9.1)$ \\
Plasma creatinine (mg/dl) & $0.8(0.1)$ \\
Plasma sodium (mEq/l) & $140(2)$ \\
Plasma potassium $(\mathrm{mEq} / \mathrm{l})$ & $3.9(0.3)$ \\
\hline
\end{tabular}

Data are mean (SD). ALT, alanine aminotransferase.

*Normal value $<280$.

†Normal value $<36$.

(FE-Li), an index of the fraction of filtered sodium load escaping proximal tubular reabsorption, were calculated from the ratio of C-Na, C-K, and C-Li to C-Cr, respectively.

Assuming that lithium is reabsorbed in the proximal tubule in parallel with sodium and water and that it is neither secreted nor reabsorbed beyond the proximal tubule, from $\mathrm{C}-\mathrm{Li}, \mathrm{U}-\mathrm{Na} \times \mathrm{V}, \mathrm{C}-\mathrm{Na}$, and $\mathrm{C}-\mathrm{Cr}$ the following parameters were derived as described by Boer et $a l^{33}$ :

Filtered sodium load $(\mathrm{Fl}-\mathrm{Na})=\mathrm{P}-\mathrm{Na} \times \mathrm{C}-\mathrm{Cr}$ ( $\mathrm{mEq} / \mathrm{min}$ )Absolute distal fluid delivery (DD)

$$
=\mathrm{C}-\mathrm{Li}(\mathrm{ml} / \mathrm{min})
$$

Absolute distal sodium delivery $(\mathrm{DDNa})=$ $\mathrm{C}-\mathrm{Li} \times \mathrm{P}-\mathrm{Na}(\mathrm{mEq} / \mathrm{min})$

Absolute distal sodium reabsorption (DRNa) $=\mathrm{DDNa}-(\mathrm{U}-\mathrm{Na} \times \mathrm{V})(\mathrm{mEq} / \mathrm{min})$

Table 2 Aldosterone and active renin levels in patients and controls

\begin{tabular}{|c|c|c|}
\hline & $\begin{array}{l}\text { Patients } \\
(n=12)\end{array}$ & $\begin{array}{l}\text { Controls } \\
(n=9)\end{array}$ \\
\hline Morning active renin $(\mu \mathrm{U} / \mathrm{ml})$ & $16.2(3.9)$ & $20.9(11.7)$ \\
\hline Morning aldosterone $(\mathrm{pg} / \mathrm{ml})$ & $80.3(43.2)$ & $112.7(51.3)$ \\
\hline Basal 1600 hour aldosterone $(\mathrm{pg} / \mathrm{ml})$ & $94.1(45.4)$ & $111.7(55.1)$ \\
\hline Aldosterone 30 minutes after metoclopramide $(\mathrm{pg} / \mathrm{ml})$ & $254.4(109.1)^{\star}$ & $195.2(65.5)^{\star}$ \\
\hline Aldosterone 60 minutes after metoclopramide $(\mathrm{pg} / \mathrm{ml})$ & $234.7(110.6)^{\star}$ & $148.4(61.6)^{\star}$ \\
\hline $\begin{array}{l}\text { Incremental aldosterone response } 30 \text { minutes after } \\
\text { metoclopramide }(\mathrm{pg} / \mathrm{ml})\end{array}$ & $160.2(68.8) \dagger$ & $83.6(35.2)$ \\
\hline $\begin{array}{l}\text { Incremental aldosterone response } 60 \text { minutes after } \\
\text { metoclopramide }(\mathrm{pg} / \mathrm{ml})\end{array}$ & $140.5(80.3) \dagger$ & $36.8(39.1)$ \\
\hline
\end{tabular}

Data are mean (SD).

${ }^{\star} \mathrm{p}<0.001$ compared with corresponding 1600 hour basal values (Student's $t$ test for paired data). $t \mathrm{p}<0.01$ compared with values in control subjects (Student's $t$ test for unpaired data).

Table 3 Renal sodium handling parameters in cirrhotic patients and in control subjects

\begin{tabular}{lll}
\hline & Patients $(n=12)$ & Controls $(n=9)$ \\
\hline Creatinine clearance $\left(\mathrm{ml} / \mathrm{min} / 1.73 \mathrm{~m}^{2} \mathrm{BSA}\right)$ & $143.6(38.6)^{\star}$ & $181.5(37.2)$ \\
Fl-Na $(\mathrm{mEq} / \mathrm{min})$ & $19.05(7.03)^{\star}$ & $30.4(6.4)$ \\
$\mathrm{U}-\mathrm{Na} \times \mathrm{V}(\mu \mathrm{Eq} / \mathrm{min})$ & $140(80)$ & $168(30)$ \\
$\mathrm{C}-\mathrm{Li}(\mathrm{ml} / \mathrm{min})$ & $30.7(9.3)$ & $27.5(6.7)$ \\
$\mathrm{FE}-\mathrm{Na}(\%)$ & $0.76(0.39)$ & $0.7(0.11)$ \\
$\mathrm{FE}-\mathrm{K}(\%)$ & $9.4(9.2)$ & $7.5(1.60)$ \\
$\mathrm{FE}-\mathrm{Li}(\%)$ & $27.5(21.2)$ & $18.2(6.4)$ \\
DDNa $(\mathrm{mEq} / \mathrm{min})$ & $4.25(1.30)$ & $3.9(1.0)$ \\
DRNa $(\mathrm{mEq} / \mathrm{min})$ & $4.14(1.23)$ & $3.7(1.06)$ \\
DFRNa I $\%)$ & $26.9(6.7)^{\star \star}$ & $12.5(3.4)$ \\
DFRNa II $(\%)$ & $97.5(1.9)$ & $93.7(2.5)$ \\
\end{tabular}

Data are mean $(\mathrm{SD})$

BSA, body surface area; U-Na, urinary sodium concentration; C-Li, renal lithium clearance; $\mathrm{FE}-\mathrm{Na}$, fractional sodium excretion; FE-K, fractional potassium excretion; FE-Li, fractional lithium excretion; Fl-Na, filtered sodium load; DDNa, absolute distal sodium delivery; DRNa, absolute distal sodium reabsorption; DFRNa I, distal fractional sodium reabsorption I; DFRNa II, distal fractional sodium reabsorption II.

${ }^{\star} \mathrm{p}<0.01,{ }^{\star \star} \mathrm{p}<0.05$ compared with controls (Student's $t$ test for unpaired data).
Distal fractional sodium reabsorption I $(\mathrm{DFRNa} \mathrm{I})=\mathrm{DRNa} / \mathrm{Fl}-\mathrm{Na}(\%)$

Moreover, distal fractional sodium reabsorption was also evaluated, in an alternative manner, as a percentage of absolute distal sodium delivery from the formula:

Distal fractional sodium reabsorption II $(\mathrm{DFRNa}$ II $)=\mathrm{DRNa} / \mathrm{DDNa}(\%)$

Finally it should be noted that, throughout the study, the expression "distal tubule" indicates all the segments of renal tubule beyond the proximal one.

\section{STATISTICAL ANALYSIS}

Results are expressed as mean (SD). Statistical analysis was performed using Student's $t$ test for paired or unpaired data ${ }^{34}$, as shown in tables 2 and 3 and fig 1. Correlation coefficients were derived using Spearman's rank correlation. ${ }^{35}$ Results were considered significant at $\mathrm{p}<0.05$. The incremental aldosterone response at 30 and 60 minutes after metoclopramide is expressed as the mean (SD) of the individual incremental aldosterone responses.

\section{Results}

Table 1 gives the main baseline clinical and laboratory findings of the cirrhotic patients. Age was not different from controls (49 (13) years).

Mean values of plasma active renin and aldosterone measured at 0800 hours in subjects in a reclining position did not differ significantly between patients and controls, both being lower in the group of cirrhotic patients (table 2). Incremental plasma aldosterone responses were significantly greater in patients than in control subjects both 30 and 60 minutes after intravenous metoclopramide administration (table 2), indicating increased endogenous dopaminergic activity in the cirrhotic group.

Table 3 shows mean data for renal sodium handling in cirrhotics and controls. Cirrhotic patients had significantly lower values for glomerular filtration rate and filtered sodium load than controls. DFRNa I was significantly higher in the preascitic cirrhotics (table 3 ).

There was a positive correlation between glomerular filtration rate and $\mathrm{C}-\mathrm{Li}$ in the control group $(r=0.64, \mathrm{p}<0.05)$ but not in patients. In the patient group inverse correlations were observed between active renin plasma levels and the following parameters: dopaminergic activity (expressed as incremental aldosterone plasma

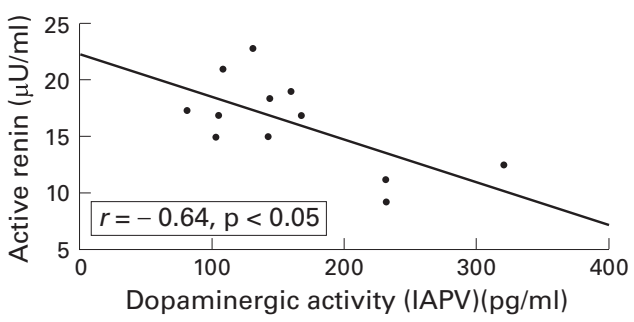

Figure 1 Inverse correlation between morning plasma levels of active renin and dopaminergic activity, evaluated from the incremental aldosterone plasma values 30 minutes after intravenous metoclopramide (IAPV), in Child-Pugh A cirrhotic patients. 


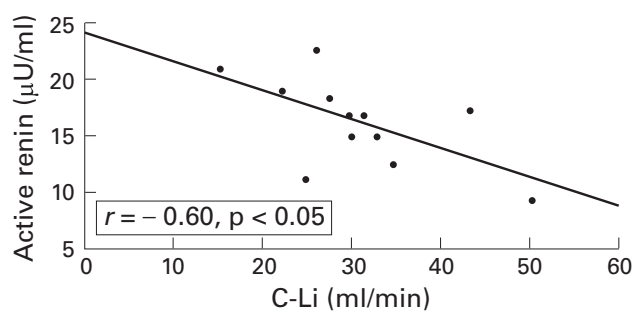

Figure 2 Inverse correlation between morning plasma levels of active renin and renal lithium clearance (C-Li), an index of fluid delivery to the loop of Henle, in Child-Pugh A cirrhotic patients.

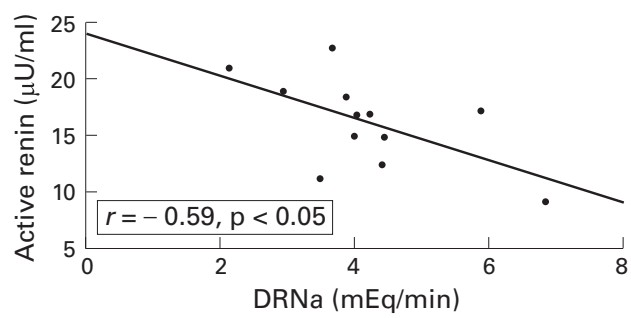

Figure 3 Inverse correlation between absolute distal tubular reabsorption of sodium (DRNa) and morning plasma levels of active renin in Child-Pugh A cirrhotic patients.

values 30 minutes after metoclopramide administration) $(r=-0.64, \mathrm{p}<0.05)$ (fig 1), C-Li $(r=$ $-0.60, \mathrm{p}<0.05)$ (fig 2$)$, and DRNa $(r=-0.59$, $\mathrm{p}<0.05$ ) (fig 3). In the cirrhotic group we found a positive correlation between $\mathrm{C}-\mathrm{Li}$ and sodium excretion $(r=0.68, \mathrm{p}<0.02)$ and an inverse one between DFRNa II and sodium excretion $(r=$ $-0.66, \mathrm{p}<0.03)$.

In the patient group, there was no significant correlation between morning plasma aldosterone levels and any of the following parameters of renal sodium handling: sodium excretion $(r$ $=-0.15, \mathrm{p}>0.05), \mathrm{DFRNa} \mathrm{I}(r: 0.09, \mathrm{p}>0.05)$ and DFRNa II $(r=0.04, \mathrm{p}>0.05)$. However, in the control group, there was a significant correlation between morning aldosterone levels and both of these parameters: DFRNa I $(r=$ $0.71, \mathrm{p}<0.05)$ and sodium excretion $(r=$ $-0.68, \mathrm{p}<0.05)$.

\section{Discussion}

Cirrhotic patients with ascites have an arterial vascular compartment that is underfilled, as arterial pressure is low despite the increased plasma volume and cardiac index. This is due to the peripheral arterial vasodilatation that occurs despite overactivity of endogenous vasoconstrictor systems - that is, secondary hyperaldosteronism, increased activity of the sympathetic nervous system, and non-osmotic hypersecretion of vasopressin. ${ }^{36-39}$

However, in preascitic cirrhosis there is good evidence that the arterial vascular bed is overfilled: three groups of investigators have reported that plasma renin activity and aldosterone are suppressed in preascitic cirrhosis. ${ }^{40-42}$ This supports the idea that there is a period of vascular overfilling before the appearance of ascites. $^{1}{ }^{24}$ This notion is also supported by the observation that cirrhotics without ascites or with early ascites formation display increased end diastolic diameters of the left ven- tricle, indicative of expanded intravascular volume. ${ }^{644}$

The total amount of sodium retained by cirrhotic patients before ascites development is dependent on the balance between sodium intake, relatively small and fixed non-renal sodium losses, and the sodium excreted in the urine.

Despite controversial findings of increased ${ }^{19}$ or decreased ${ }^{16-18}$ glomerular filtration rate in preascitic cirrhosis, these patients are unable to handle an oral or intravenous sodium load, indicating increased tubular (proximal or distal) sodium retention even in the presence of preserved glomerular filtration rate. ${ }^{20-22}$

On average, our patients displayed clearly, although not significantly, reduced concentrations of plasma aldosterone and active renin compared with controls (table 2). Unlike previous studies, which identified suppressed plasma renin activity at this disease stage, ${ }^{40-42}$ we measured the circulating concentration of active renin protein by an immunoradiometric assay. In effect, patients with liver cirrhosis may have decreased plasma levels of renin substrate - that is, angiotensinogen - which leads to an underestimation of renin concentration when measured as plasma renin activity. ${ }^{45} 46$

Compared with controls, our patients showed evidence of increased endogenous dopaminergic activity, expressed as higher incremental plasma aldosterone response after intravenous injection of the antidopaminergic drug metoclopramide (table 2). This well recognised test takes advantage of the inhibitory effect of endogenous dopamine on adrenal mineralocorticoid secretion. ${ }^{47-49}$ In other words, the higher the incremental aldosterone response after metoclopramide, the higher the baseline endogenous dopaminergic activity counteracting aldosterone secretion.

Based on the data presented, the increased dopaminergic activity seems to be a reliable marker of an expanded central fluid volume, as we found an inverse correlation between active renin and the incremental aldosterone response after metoclopramide administration (fig 1). This is supported by the previous observation that plasma dopamine increases after saline infusion or head-out water immersion in normal men, ${ }^{12}{ }^{13}$ both procedures being able to increase central plasma volume acutely.

The increased dopaminergic function and the decreased circulating immunoreactive renin and aldosterone suggest that there was overfilling of the vascular bed in our group of preascitic cirrhotics while on a normal sodium diet.

In order to identify the site of increased sodium reabsorption in the nephron, we studied our patients using the lithium clearance and fractional excretion technique. ${ }^{24}{ }^{25}$ The following conclusions are based on the assumption that $\mathrm{C}-\mathrm{Li}$ is an index of proximal sodium reabsorption. It should be noted that the mean FE-Na in our cirrhotic patients exceeded the threshold below which the reliability of C-Li as an index of salt and fluid delivery from the proximal tubule is questionable. In fact, studies 
in humans showed that a decrease in C-Li due to lithium reabsorption beyond the proximal tubule occurs only at values of FE-Na close to $0.02 \%$. $^{32} 50-52$

According to previous literature, ${ }^{16-18}$ our preascitic cirrhotics had a lower glomerular filtration rate and filtered sodium load than controls, although they did not exhibit hyponatraemia or hyperreninaemia. They also displayed a higher distal fractional reabsorption of sodium (expressed as a percentage of Fl-Na) (table 3). These data suggest that the proximal tubule is unlikely to be the segment of the nephron responsible for the enhanced sodium retention in the preascitic patient.

The inverse correlation of active renin with $\mathrm{C}-\mathrm{Li}$ (fig 2) actually underlines a compensatory role for the proximal renal tubule. In other words, it is able to deliver more fluid and sodium to the loop of Henle during a progressive increase in circulating fluid volume. Indeed, this compensatory role could be due to the increased dopaminergic activity we identified in patients, as dopamine exerts strong diuretic and natriuretic effects acting on renal cortical dopamine ${ }_{1}$ receptors, and inhibits the $\mathrm{Na}^{+}-\mathrm{K}^{+}$-ATPase activity in proximal tubule segments. ${ }^{53}$ At this disease stage, this mechanism of compensation is efficient, as C- $\mathrm{Li}$ also correlated directly with net sodium excretion.

In contrast, the avidity of the sodium retention displayed by the distal nephron, which is increased in patients with respect to healthy controls, is critical in regulating the increased central fluid volume and the net sodium excretion, because absolute distal reabsorption of sodium correlates inversely with the active renin plasma levels (fig 3), and DFRNa II correlates inversely with sodium excretion.

Our data indicate that there is enhanced sodium retention in the distal tubule, but this is not related to plasma aldosterone. In effect the net sodium excretion and the fractional distal sodium reabsorption were clearly independent of basal aldosterone plasma concentrations, as already shown in recumbent preascitic cirrhotics. $^{91655}$ In contrast, in the control group, we found the predicted correlations between morning aldosterone levels and both of these parameters: DFRNa I and sodium excretion.

In other studies dealing with preascitic cirrhosis, Simòn et $a l^{26}$ observed that $\mathrm{C}-\mathrm{Li}$ and fractional proximal sodium reabsorption were not different from control subjects, and Wong et $a l^{27}$ identified reduced values of $\mathrm{FE}-\mathrm{Li}$ in patients with compensated alcoholic cirrhosis. However, Wong et $a l^{27}$ observed an increased glomerular filtration rate in those compensated cirrhotics, an observation at variance with others. ${ }^{16-18}$ In agreement with our results, the same investigators also noted that the values of distal tubular reabsorption of sodium (expressed as the reabsorbed percentage of distal delivery of sodium) were increased in patients compared with controls. ${ }^{27}$

Recently, in rats with experimental liver cirrhosis Jonassen et $a \bar{p}^{6}$ observed a consistent increase in the volume of the thick ascending limb of the loop of Henle epithelium and increased $\mathrm{NaCl}$ reabsorption at this nephron site, an aldosterone independent tubule segment. Our results and those of Jonassen et al are clearly at variance with the previous observation by Wood et $a l^{22}$ who deduced avid proximal tubular reabsorption of sodium in compensated cirrhosis by using the free water clearance technique in the presence of hypotonic diuresis. ${ }^{22}$ This technique, now obsolete because of the introduction of the lithium clearance and fractional excretion measurement, is based on the assumption that water loading abolishes antidiuretic hormone secretion and that the distal nephron is impermeable to water in the absence of this hormone. It is generally accepted, however, that this technique underestimates tubular fluid delivery to the loop of Henle because of antidiuretic hormone independent distal water reabsorption in the thin descending limbs of the loop of Henle and the collecting ducts. ${ }^{57} 58$

In conclusion, in our group of non-azotemic preascitic cirrhotics, we have confirmed enhanced responses of plasma aldosterone to intravenous metoclopramide (an expression of increased activity of the dopaminergic system) and the depression of the renin-aldosterone axis, all suggesting an increased central fluid volume. This phenomenon could be related, at least in our patients, to a decreased glomerular filtration rate and filtered sodium load and the enhanced fractional distal tubular reabsorption of sodium.

This work was supported by grants from the Ministero della Università e della Ricerca Scientifica $(60 \%), 1996$, and of the Società Italiana Gastroenterologia (SIGE), 1997. We thank Dr Kevin Moore (Royal Free Hospital School of Medicine, London, UK) for a preliminary revision of the paper. This study was presented in oral form at the 1998 Annual Meeting of the Italian Association for the Study of the Liver (AISF), Rome, Italy, February 1998 and in oral form at the 33rd Annual Meeting of the European Association for the Study of the Liver (EASL), Lisbon, Portugal, April 1998.

1 Levy M. Sodium retention and ascites formation in dogs with experimental portal hypertension. Am 7 Physiol with experimental

2 Levy M, Allotey JBK. Temporal relationships between urinary salt retention and altered systemic hemodynamics in dogs with experimental cirrhosis. F Lab Clin Med 1978; 92:560-9.

3 Jimènez W, Martìnez-Pardo A, Arroyo V, et al. Temporal relationship between hyperaldosteronism, sodium retention and ascites formation in rats with experimental cirrhosis. Hepatology 1985;5:245-50.

4 Lieberman FL, Reynolds TB. Plasma volume in cirrhosis of the liver: its relation to portal hypertension, ascites and renal failure. $\mathcal{F}$ Clin Invest 1967;46:1297-308.

5 Wong F, Liu P, Tobe S, et al. Central blood volume in cirrhosis: measurement with radionuclide angiography. Hepatology 1994;19:312-21.

6 Lewis FW, Adair O, Rector WG Jr. Arterial vasodilatation is not the cause of increased cardiac output in cirrhosis. Gastroenterology 1992;102:1024-9.

7 Wilkinson SP, Smith JK, Clarke M, et al. Intrarenal distribution of plasma flow in cirrhosis as measured by transit renography: relationship with plasma renin activity and sodium and water retention. Clin Sci Mol Med 1977;52: $469-75$.

8 Wilkinson SP, Smith JK, Williams R. Changes in plasma renin activity in cirrhosis: a reappraisal based on studies in 67 patients and "low renin" cirrhosis. Hypertension 1979;1: $125-9$.

9 Trevisani F, Bernardi M, Gasbarrini A, et al. Bed-restinduced hypernatriuresis in cirrhotic patients without ascites: does it contribute to maintain "compensation"? $\mathcal{f}$ Hepatol 1992;16:190-6.

10 Rector WG Jr, Adair O, Hossack KF, et al. Atrial volume in cirrhosis: relationship to blood volume and plasma concentration of atrial natriuretic factor. Gastroenterology 1990;99: 766-70.

11 Sansoè G, Ferrari A, Baraldi E, et al. Endogenous dopaminergic activity in Child-Pugh A cirrhosis: potential role in renal sodium handling and in the maintenance of clinical compensation. Eur f Clin Invest 1998;28:131-7. 
12 Krishna GC, Danovitch GM, Sowers JR. Catecholamine responses to central volume expansion produced by head-
out water immersion and saline infusion. 7 Clin Endocrinol Metab 1983;56:998-1002.

13 Krishna GC, Danovitch GM, Beck FWJ, et al. Dopaminergic mediation of the natriuretic response to volume expansion. F Lab Clin Med 1985;105:214-18.

14 Schrier RW, Arroyo V, Bernardi M, et al. Peripheral arterial vasodilatation hypothesis: a proposal for the initiation of renal sodium and water retention. Hepatology 1988;8: 1151-7.

15 Groszmann RJ. Vasodilatation and hyperdynamic circulatory state in chronic liver diseases. In: Bosch J, Groszmann RJ, eds. Portal hypertension: pathophysiology and treatment. Oxford: Blackwell Scientific Publications, 1994:17-26.

16 Trevisani F, Bernardi M, De Palma R, et al. Circadian variation in renal sodium and potassium handling in cirrhosis. Gastroenterology 1989;96:1 187-98.

17 De Santo NG, Anastasio P, Loguercio C, et al. Glucagonindependent renal hyperaemia and hyperfiltration after an oral protein load

18 Woitas RP, Heller J, Stoffel-Wagner B, et al. Renal functional reserve and nitric oxide in patients with compensated cirrhosis. Hepatology 1997; 26:858-64.

19 Wong F, Massie D, Colman J, et al. Glomerular hyperfiltration in patients with well-compensated alcoholic cirrhosis Gastroenterology 1993;104:884-9.

20 Papper S, Rosenbaum JD. Abnormalities in the excretion of water and sodium in "compensated" cirrhosis of the liver. $\mathcal{F}$ Lab Clin Med 1952;40:523-30.

21 Caregaro L, Lauro S, Angeli P, et al. Renal water and sodium handling in compensated liver cirrhosis: mechanism of the impaired natriuresis after saline loading. Eur $\mathcal{F}$ Clin Invest 1985;15:360-5.

22 Wood LJ, Massie D, McLean AJ, et al. Renal sodium retention in cirrhosis: tubular site and relation to hepatic disfunction. Hepatology 1988;8:831-6.

23 Ginès P, Fernàndez-Esparrach G, Arroyo V, et al. Pathogenesis of ascites in cirrhosis. Semin Liver Dis 1997;17:175-89.

24 Thomsen K. Lithium clearance: a new method for determining proximal and distal tubular reabsorption of sodium and water. Nephron 1984;37:217-23.

25 Strazzullo P, Iacoviello I, Iacone R, et al. Use of fractional lithium clearance in clinical and epidemiological investigation: a methodological assessment. Clin Sci 1988; 74:651-7.

26 Simòn MA, Diez J, Prieto J. Abnormal sympathetic and renal response to sodium restriction in compensated cirrhosis. Gastroenterology 1991;101:1354-60.

27 Wong F, Massie D, Hsu P, et al. Renal response to a saline load in well-compensated alcoholic cirrhosis. Hepatology 1994;20:873-81.

28 Pugh RNH, Murray-Lyon IM, Dawson JL, et al. Transection of the esophagus for bleeding esophageal varices. $\mathrm{Br} \mathcal{F}$ Surg 1973;60:646-9.

29 Gniadek TC, Grekin RJ, Gross MD, et al. Hyperresponsiveness of aldosterone to metoclopramide in aldosresponsiveness of aldosterone to metoclopr

30 Ganguly A, Pratt JH, Weinberger $\mathrm{MH}$, et al. Differing effects of metoclopramide and adrenocorticotropin on plasma
aldosterone levels in glucocorticoid-suppressible hyperaldosteronism and other forms of hyperaldosteronism. F Clin dosteronism and other forms of hyper
Endocrinol Metab 1983;57:388-92.

31 Bartels H, Bohmer M. Eine mikromethode zur kreatinibestimmung. Clin Chim Acta 1971;32:81-5.

32 Thomsen K, Olsen OV. Renal lithium clearance as a measure of the delivery of water and sodium from the proximal tubule in humans. Am f Med Sci 1984;288:158-61.

33 Boer WH, Koomans HA, Dorhout Mees EJ. Lithium clearance during paradoxical natriuresis of hypotonic expansion in man. Kidney Int 1987;32:376-81.

34 SAS Institute. SAS User's Guide: Statistics. Cary, NC: SAS Institute, 1982:139-99.

35 Siegel S. Measures of correlation and their tests of significance. In: Siegel S, ed. Non-parametric statistics for the
behavioral sciences. New York: McGraw-Hill, 1956:195239.

36 Bosch J, Arroyo V, Betriu A, et al. Hepatic hemodynamics and the renin-angiotensin-aldosterone system in cirrhosis. Gastroenterology 1980;78:92-9.
37 Fernàndez-Seara J, Prieto J, Quiroga J, et al. Systemic and renal hemodynamics in patients with liver cirrhosis and ascites with and without functional renal failure. Gastroenterology 1989;97:1304-12.

38 Henriksen JH, Bendtsen F, Gerbes AL, et al. Estimated central blood volume in cirrhosis: relationship to sympathetic nervous activity, $\beta$-adrenergic blockade and atrial natriuretic factor. Hepatology 1992;16:1163-70.

39 Maroto A, Ginès $\mathrm{P}$, Arroyo V, et al. Brachial and femoral artery blood flow in cirrhosis: relationship to kidney dysfunction. Hepatology 1993;17:788-93.

40 Bernardi M, Trevisani F, Santini C, et al. Aldosterone related blood volume expansion in cirrhosis before and during the early phase of ascites formation. Gut 1983;24: 761-6.

41 Wilkinson SP, Williams R. Renin-angiotensin-aldosterone system in cirrhosis. Gut 1980;21:545-54.

42 Wernze H, Speck HJ, Muller G. Studies on the activity of the renin-angiotensin-aldosterone system in patients with cirrhosis of the liver. Klin Wochenschr 1978;56:389-97.

43 Levy M, Wexler MJ. Renal sodium retention and ascites formation in dogs with experimental portal cirrhosis but without portal hypertension or increased splanchnic vascular capacity. F Lab Clin Med 1978;91:520-36.

44 Rector WGJr, Robertson $\mathrm{AD}$, Lewis FW, et al. Arterial underfilling does not cause sodium retention in cirrhosis. Am ₹ Med 1993;95:286-95.

45 Plouin PF, Cudek P, Arnal JF, et al. Immunoradiometric assay of active renin versus determination of plasma renin activity in the clinical investigation of hypertension, congestive heart failure and liver cirrhosis. Horm Res 1990; 34:138-41.

46 Asbert M, Jimènez W, Gaya J, et al. Assessment of the reninangiotensin system in cirrhotic patients: comparison between plasma renin activity and direct measurement of immunoreactive renin. 7 Hepatol 1992;15:179-83.

47 Carey RM, Thorner MO, Ortt EM. Dopaminergic inhibition of metoclopramide-induced aldosterone secretion in man. Dissociation of responses to dopamine and bromocriptine. F Clin Invest 1980;66:10-18.

48 Gordon MB, Moore TJ, Dluhy RG, et al. Dopaminergic modulation of aldosterone responsiveness to angiotensin II with changes in sodium intake. 7 Clin Endocrinol Metab 1983;56:340-5.

49 Malchoff CD, Hughes J, Sen S, et al. Dopamine inhibits the aldosterone response to upright posture. 7 Clin Endocrinol Metab 1986;63:197-201.

50 Atherton JC, Green R, Hughes S, et al. Lithium clearance in man: effects of dietary salt intake, acute changes in extracellular fluid volume, amiloride and furosemide. Clin Sci 1987;73:645-51.

51 Solomon LR, Atherton JC, Bobinski H, et al. Effect of dietary sodium chloride and posture on plasma immunoreactive atrial natriuretic peptide concentration in man. Clin Sci 1987;72:201-8.

52 Boer WH, Koomans A, Dorhout Mees EJ, et al. Lithium clearance during variations in sodium intake in man: effects of sodium restriction and amiloride. Eur F Clin Invest 1988; 18:279-83.

53 Aperia A, Bertorello A, Seri I. Dopamine causes inhibition of $\mathrm{Na}^{+}-\mathrm{K}^{+}$-ATPase activity in rat proximal convoluted tubule segments. Am f Physiol 1987;252:F39-45.

54 Ortola FV, Seri I, Downes S, et al. Dopamine -receptor $^{-}$ blockade inhibits ANP-induced phosphaturia and calciuria in rats. Am 7 Physiol 1990;259:F138-46.

55 Bernardi M, Trevisani F, Gasbarrini A, et al. Hepatorenal disorders: role of the renin-angiotensin-aldosterone system. Semin Liver Dis 1994;14:23-34.

56 Jonassen TEN, Marcussen N, Haugan K, et al. Functional and structural changes in the thick ascending limb of Henle's loop in rats with liver cirrhosis. Am f Physiol 1997;273: R568-72.

57 Bartoli E, Branca GF, Satta A, et al. Sodium reabsorption by the Henle's loop in humans. Nephron 1987;46:288-300.

58 Boer WH, Henè RJ, Koomans HA, et al. Discrepancy between lithium and free water clearance in patients with Bartter's syndrome. Nephron 1994;67:82-7. 